\title{
Discussion on School Physical Education Development Ideas Based on 'Health China' Environment
}

\author{
Jing Li \\ Sect. Of P.E, Wuhan Univ. Of Tech., Wuhan 430070, China.
}

Keywords: Health China; school physical education; development ideas.

\begin{abstract}
In the paper, the development of school physical education is studied under the background of 'Health China' by means of literature review method and logical analysis method. Current development advantages and development trend of school physical education under the support of many documents are described through reading and studying a series of state-issued relevant documents about 'Health China' and 'School Physical Education'. The author believes that the development of school physical education is indispensable to relevant suggestions proposed for 'Health China', and the defects in modern school physical education development are also discovered. The development of school physical education should be considered in four aspects:(1) to improve the importance attached by the school to physical education class and create sound physical education atmosphere; (2) to improve the comprehensive level of physical education teachers; (3) to improve the construction of venue and equipment facilities; (4) to strengthen extracurricular and extracurricular physical education activities, thereby laying foundation for improving students' physical quality, strengthening national constitution, training competitive physical education talents, and realizing the great ideal of 'Health China'.
\end{abstract}

\section{Introduction}

General Secretary Xi Jinping points out that the state gives priority to develop people's health in the strategic position, and regards popularization of healthy living, optimization of health services, improvement of health care guarantee, construction of health environment and development of health industry as the key points, thereby accelerating construction of Health China, and making efforts to safeguard people's health comprehensively in whole cycle [1]. The development of school physical education is the starting point to realize the goal of Health China, the students' physical health is related to the development of the society, which determines the future of the country. It is the first priority to strengthen school physical education actually and improve students' physical quality comprehensively. It is proposed in 'China School Physical Education Development Report (2015)' that the young is strong, the country is strong, promotion of adolescent physical health is the foundation of success and happiness in life, and it is related to national health, adolescent health is regarded the 'base' for current universal health, and 'foundation' of national health in the future. The state should pay attention to children and control from the basis [2]. As the foundation for improving the physical quality of residents, school physical education plays a role in promoting the national fitness, and the realization of Health China and national fitness is inseparable from the development of school physical education.

\section{Essence of Health China}

'Health China 2030 Planning Outline' refers that people's physical health is regarded as the core to improve people's physical quality, develop people' s effective understanding to strengthen physical exercise vigorously, and participate in physical training environment actually, and a plan is formulated to guarantee people's physical health. Health China is the struggling goal of our people to show brand-new images to the world in the new journey of comprehensively building a moderately prosperous society in all respects and realizing the great rejuvenation of the Chinese nation [3]. Health 
is an inevitable requirement for promoting comprehensive development of people. It is the basic condition of economic and social development, an important symbol of national prosperity and national strength, and a common pursuit of the masses. Health should include physical, mental and behavioral dimensions, etc., including physical, psychological, social and lifestyle factors, etc. [4]. After the 18th National People's Congress of the Party was held, the Party Central Committee with Comrade Xi Jinping as the core insists on people-oriented development ideas, which promotes 'Health China' to the position of national strategy, health education is listed into national education system, health education is regarded as an important content of quality education in all education stages, thereby opening up a sanitation and health development road consistent with China's national conditions [5]. Health priority: health is regarded as priority for development in a strategic position. The concept of promoting health is integrated into the whole process of formulating and implementing public policies based on national conditions, thereby speeding up the formation of healthy way, ecological environment as well as economic and social development pattern beneficial for health, and realizing benign coordinated development of health and economic society [6].

\section{Advantages of School Physical Education Development Under the Background of Health China}

\subsection{Policy Support to School Physical Education Development under the Background of Health China Background.}

The world 'health' is more and more emphasized in current society. National health is the guarantee of realize China Dream and great rejuvenation. The State issued documents about national fitness, Health China, strengthening of school physical education construction, etc. successively since 1995. Emphasis on healthy development of children and adolescents is mainly stressed. Children and teenagers are the future of the state and hope of the nationality. Improvement of health level and enhancement of physical quality are important conditions for motherland prosperity and restoration. The follows are stressed in 'Suggestion about Strengthening School Physical Education to Promote Comprehensive Development of Students' (1) to insist on combination of classroom teaching and extracurricular activities, ensure adequate course time, guarantee the class efficiency, strengthen extracurricular physical exercise, and ensure that students can exercise for an hour every day; (2) to insist on combination of group activities and sports competition, carry out practical and effective extracurricular activities and physical education competitions in the school, train students' interest in physical education, lay foundation for cultivating physical education talents, create sound physical education atmosphere in the school, and comprehensively improve the students' physical quality; (3) to insist on combination of comprehensive promotion and classified guidance, unify standards by the government, adjust measures to local conditions, be creative, actively participate in physical education events combined with local ethnic characteristics, and improve school physical education work level comprehensively; Central Committee and the State Council jointly issued 'Central No. 7 Document', which is combined with sunlight physical education, 'sunlight physical education sports' can become the physical education policy that must be implemented in all schools. Meanwhile, the status of physical education in schools is also improved, thereby playing a practical role for school physical education development.

\subsection{Strengthening of Emphasis on School Physical Education Teacher Under the Background of Health China}

Most schools don't pay much attention to PE teachers. It is generally believed that PE teachers are easy to work with fewer tasks, the curriculum is simple, and lesson preparation is not required. The erroneous concept has been popular among non-physical education workers. In fact, the tiredness of physical education teachers is not lower than teachers of other subjects, PE teachers also should prepare lessons, class-break setting-up exercises, school sports meeting and extracurricular physical education activities should be carefully and rigorously planned for implementation, thereby ensuring the safety and order thereof, improving students' physical quality, and promoting students' physical 
health as purposes. The State issues documents about strengthening and improving school physical education. It is emphasized in the documents that construction of physical education teacher team should be strengthened, the physical education teachers' sense of honor should be enhanced, physical education teachers should be trained, training plan to teachers in primary and secondary schools should be implemented, and rural teachers in the Midwest China should be trained mainly. The teachers of physical education are in accordance with the teachers of other school subjects in the aspects of professional title evaluation, appraisal, welfare treatment, etc.

\subsection{Strengthening of Guarantee of School Physical Education Expense under the Background of Health China.}

Smooth school physical education depends on funding support. 'Suggestion about Strengthening School Physical Education to Promote Comprehensive Development of Students' shows that governments at all levels must strengthen fund investment on school physical education, education bureaus at all levels should include school physical education expense into the annual budget, thereby giving strong support to school physical education. High fund investment is required for construction of school physical education. School venue facilities and equipment purchase, school sports meeting and participation in competitions outside the school are guaranteed powerfully. In addition, social fund investment in school physical education is encouraged, fund can be raised for developing school physical education in many modes, thereby guaranteeing construction and development of school physical education powerfully.

\section{Development ideas of school physical education under the background of Health China}

\subsection{Improvement of the Importance Attached By the School to Physical Education Class and Creation of Sound Physical Education Atmosphere.}

School is a place for student enlightenment. Physical exercise also should be emphasized since childhood. Schools should improve students' interest training in physical education since childhood, instill the importance of physical exercise for mental and physical health, and encourage students to participate in physical exercise actively and effectively. Children, adolescents, teenagers or adults require certain amount of physical exercise in daily life. School physical education atmosphere is particularly important. It is obvious that physical education class is set in four stages of elementary school, junior middle school, senior middle school and university basically with different emphasis degrees. The physical education class in elementary school should be based on cultivating students' interests. Physical quality is exercised through physical education class on the one hand, the setting of physical education events also should be emphasized on the other hand. Many physical education events are set according to concrete conditions of the school as physical education exercise in physical education class and extracurricular activities. Students can select own favorite events according to the physical education events in the school, thereby exercising the body and cultivating interests. Most importantly, students acquire own specialty. Junior middle school and senior middle school should should develop students' own specialty mainly according to school condition, and students also should participate in other physical education events for multi-skill physical education exercise in a complementary mode. Students not only can improve own physical education specialty skills, but also can learn other physical education events, which is beneficial for future development thereof. However, the activities can be concretely implemented according to concrete condition of the school, such as the physical education event selection in the school. Students also can select own interested events for exercise even if there are no advantageous events. The teaching mode of senior middle school and junior middle school can be extended in university physical education class. Relevant documents are issued by the State. The documents show that physical education competition for students should be improved and standardized, a series of competition systems can be formed, including county, municipal, provincial and national competitions. Therefore, the activities include school sports meeting organized unilaterally by the school on the one hand, students also can 
participate in competitions at higher level. School physical education can be strengthened, and a very powerful atmosphere is created.

\subsection{Improvement of Comprehensive Level of PE Teachers.}

Teacher is the main body to impart knowledge and important implementer for training talents. Therefore, it is of great importance to improve the comprehensive level of PE teachers. Teachers should master multiple skills. Students' participation in physical exercises is determined by comprehensive level of teachers themselves in in primary school, junior middle school, senior middle school or university. Physical education teachers should study in many aspects. Physical education teachers should master many physical education techniques rather than single technique from the technical level. Teachers teach all students rather than one special training class in the school environment, therefore teachers should teach many physical education events to students in annual teaching syllabus and plan for the whole academic year, they should cultivate students' interests in physical education, thereby students can choose own speciality or interested physical education events for exercise effectively. Teachers not only should teach students physical education skills outdoors, but also should teach students relevant theory knowledge according to theory knowledge, including explanation of introduction and development of various physical education events. In addition, sports training, sports anatomy, sports physiology, sports psychology, sports nutrition and knowledge of other related disciplines also should be taught. Therefore, students can understand exercise purpose and significance during exercise. Students can fully comprehend and understand physical education, practice should be combined with theory, thereby students can participate in physical exercise more sufficiently.

\subsection{Improvement of Venue and Equipment Facility Construction.}

The quality and safety of school physical education facilities are directly related to healthy development of school physical education. More importantly, students' life safety is also threatened [7]. Previous media reports indicated poison grass and poison track in schools as well as a series of problems about adverse venues and equipment, which produce serious harm to healthy body of students and further damage normal school physical education under the concept of Health China. School physical education venue and equipment are also regarded as a double-edged sword. Qualified physical education equipment can be used by students $t$ safely, which is beneficial for student's mental and physical state. On the contrary, unqualified physical education equipment may affect students' participation in the physical education events in mild condition, and students' life may be threatened in severe condition. It is an irreparable mistake for parents, schools and society. Documents issued by the State points out that 'governments at various levels should practically increase fund investment in school physical education, local people's governments at various levels should give priority to school physical education during arrangement of fiscal transfer payment funds and financial resources at the corresponding level'. It is obvious that the State invests a lot of fund in the aspects of development and constructing school physical education. Unqualified physical education venues and equipment facilities should be prevented from campus, which should be controlled strictly. Schools can construct and maintain physical exercise venues and increase physical education event equipment facilities through funds. National documents show that schools should vigorously promote the collective events such as football, basketball, volleyball, etc. as well as advantage events such as table tennis, badminton, martial arts, etc. Schools can purchase sufficient related physical education tools with fund, thereby ensuring that all students can use own activity equipment in the physical education class.

\subsection{Strengthening of Extracurricular and Extracurricular Physical Education Activities.}

School should actively carry out extracurricular activities and extracurricular activities so as to ensure that students can exercise for an hour every day, thereby laying a foundation for improving the physical quality of students. Currently, extracurricular activity time is reserved basically in the afternoon for all schools of many provinces and cities. Different time periods are determined according to different school conditions. Related policies launched by the state are also responded actively. Extracurricular activities are set in the school, students can relax in one-day busy schoolwork. 
Brain can be relaxed mentally, pressure can be alleviated, and thinking can be activated through physical exercise, thereby learning academic class better. students can stretch their muscles, move their bodies, and prevent obesity physically, and toxins can be excreted from the body through sweat. Students can achieve cheerful mood psychologically through physical exercise, which is greatly beneficial for reducing school pressure and preventing depression, thereby reducing the incidence of students' psychological diseases. Schools should participate in exercise scientifically and rationally on the basis of students' growth development characteristics and characteristics of various physical education events. Meanwhile, they should deal with the relationship between physical exercise and literacy class. The technical level of physical exercise can be improved on the basis of not affecting academic results. Schools can construct class sports team, grade sports team and school sports team for training or cultivating talents according to actual condition, thereby actively participating in extracurricular physical education activities and competitions. Meanwhile, competitive physical education reserve talents also can be cultivated for municipal team, provincial team and national team.

\section{Conclusion}

School physical education development is correlated to social development and progress. The future of the country is determined by physical health of children and adolescents. Development and construction of school physical education should be strengthened, therefore students can actively participle in physical exercise. They can strive for a good future for themselves, and make contribution to national progress under the condition of guaranteeing own physical health. Children and school should be emphasized for realizing 'Health China'. Physical exercises can be implemented in school classrooms effectively.

\section{References}

[1]. Liu Guoyong. Implementation of national fitness strategy and promotion of Health China construction; Physical Education Science,2016,36(12):3-10;

[2]. China School Physical Education Development Report (2015); Beijing: Higher Education Press, 2015;

[3]. Li Tao, Wang Xiufeng. Connotation and realization path of Health China; Health Economic Research, 2016, (1):4-10;

[4]. Liu Guoyong. Implementation of national fitness strategy and promotion of Health China construction; Physical Education Science, 2016,36(12):3-10;

[5]. Printing and issuance of 'Health China' 2030' Planning Outline' by The CPC Central Committee and State Council; Bulletin of The State Council of the People's Republic of China, 2016,(32):5-20;

[6]. Liu Shupeng, Li Yanchao. Research on China school physical education reform and development ideas from the perspective of Health China. Guizhou Physical Education Science and Technology, 2017, (2):23-26+29. 